\title{
CFD-Based Numerical Simulation of Water Film Flash Evaporation with a New Flash Evaporation Model
}

\author{
Siyuan Zhao ${ }^{1} \cdot$ Yong Liu ${ }^{2} \cdot$ Yanjun Liu ${ }^{1} \cdot$ Ping Na ${ }^{1}$ \\ Received: 12 April 2018 / Revised: 15 May 2018 / Accepted: 22 May 2018 / Published online: 18 July 2018 \\ (c) The Author(s) 2018
}

\begin{abstract}
In this study, a new mass model involving superheat, initial temperature, liquid height, evaporator diameter, and flashing time is established to describe the flash evaporation process of water film. Of 469 sets of flash experimental data from three previous researches, 305 sets were applied to optimize parameters, and the other 164 sets were used to verify the practicability of the model. The results showed that the mean relative error between the literature data and the model values was less than $16.3 \%$, and the model statistics proved that the model was well-posed. Then, the kinetic model was obtained using the time derivative of the new mass model. Computational fluid dynamics simulation of water film flash evaporation was studied based on a user-defined function program of the new evaporation kinetic model. The new kinetic model shows more consistency with the experimental phenomena in terms of evaporated mass and temperature compared with the evaporation-condensation model in Fluent software and Gopalakrishna's model. This new kinetic model can be extended to describe the flash process of water solution under other conditions.
\end{abstract}

Keywords Flash evaporation · Evaporation model · Well-posedness analysis · CFD simulation

\section{List of symbols}

C Salt concentration (\%)

$C_{\mathrm{p}} \quad$ Specific heat capacity of liquid $[\mathrm{J} /(\mathrm{kg} \mathrm{K})]$

$D \quad$ Diameter or hydraulic diameter of container (m)

$H \quad$ Liquid height (m)

$h_{\mathrm{fg}} \quad$ Latent heat of vaporization $(\mathrm{J} / \mathrm{kg})$

$k \quad$ Thermal conductivity of liquid [W/(m K)]

$m_{\mathrm{ev}} \quad$ Volumetric evaporated mass of liquid $\left(\mathrm{kg} / \mathrm{m}^{3}\right)$

$m_{\mathrm{ev}}^{\mathrm{f}} \quad$ Final volumetric evaporation mass of liquid $\left(\mathrm{kg} / \mathrm{m}^{3}\right)$

$\Delta p \quad$ Pressure drop $(\mathrm{Pa})$

$p_{0} \quad$ Operating pressure $(\mathrm{kPa})$

$p^{*} \quad$ Vapor pressure $(\mathrm{kPa})$

$t \quad$ Flash evaporation time (s)

$T_{0} \quad$ Initial temperature $\left({ }^{\circ} \mathrm{C}\right)$

$T_{\mathrm{e}} \quad$ Equilibrium temperature $\left({ }^{\circ} \mathrm{C}\right)$

Electronic supplementary material The online version of this article (https://doi.org/10.1007/s12209-018-0171-5) contains supplementary material, which is available to authorized users.

Ping Na

naping@tju.edu.cn

1 School of Chemical Engineering and Technology, Tianjin University, Tianjin 300350, China

2 School of Environmental Engineering and Technology, Tianjin University, Tianjin 300350, China
$\Delta T \quad$ Superheat temperature $\left({ }^{\circ} \mathrm{C}\right)$

$\nu_{\mathrm{ev}}$ Instantaneous volumetric evaporation flow rate $[\mathrm{kg} /$ $\left.\left(\mathrm{m}^{3} \mathrm{~s}\right)\right]$

$y_{i} \quad$ Experimental value

$\hat{y}_{1} \quad$ Calculated value

\section{Greek symbols}

$\rho_{1} \quad$ Density of liquid $\left(\mathrm{kg} / \mathrm{m}^{3}\right)$

$\rho_{\mathrm{v}} \quad$ Density of vapor $\left(\mathrm{kg} / \mathrm{m}^{3}\right)$

$\sigma \quad$ Surface tension $(\mathrm{N} / \mathrm{m})$

Dimensionless numbers

Pr Prandtl number of liquid

\section{Introduction}

Evaporation is a basic unit operation of chemical engineering. When the liquid temperature is higher than the equilibrium temperature because of a sudden pressure drop, an extreme evaporation phenomenon known as flash evaporation occurs. This is common during crystallization, dehydration, and distillation processes. Many experiments have since been carried out to study the heat and mass transfers of flash evaporation process.

A series of experiments were carried out by Liu et al. [1] to investigate the free water surface evaporation, and a 
function of the ratio between vapor pressure gradient and temperature gradient was introduced to evaluate the heat transfer rate. Zhang et al. [2, 3] mainly studied the heat transfer characteristics of circulatory flash evaporation of pure water and $\mathrm{NaCl}$ aqueous solution. Miyatake et al. [4, 5] investigated the effect of liquid temperature on water film flash evaporation under $40-80{ }^{\circ} \mathrm{C}$ and film heights of 119-250 mm. Saury et al. [6] studied the flash evaporation of a $15-\mathrm{mm}$ water film with superheats of $1-35^{\circ} \mathrm{C}$ and initial temperature of $30-75{ }^{\circ} \mathrm{C}$ and found a correlation between the evaporated mass and superheats.

To date, several flash evaporation models have been presented to estimate the flash evaporation process. The Hertz-Knudsen-Schrage equation [7], based on classical thermodynamics, can be used to determine evaporation rates with evaporation and condensation coefficients. Badam et al. [8] used the Hertz-Knudsen-Schrage equation to estimate evaporation rates by evaporation and condensation coefficients, but the results were much smaller than the experimental results. A traditional evaporation-condensation model in ANSYS Fluent software, which is based on the Hertz-Knudsen-Schrage equation, has also been proposed, but the coefficients are affected by the change of liquid temperature in the real flash evaporation process. Cheng et al. $[9,10]$ established a flash evaporation model considering film flash and droplet flash processes based on the film-penetration theory and evaporation model. Aoki [11] found that the maximum heat flux of evaporation is proportional to the superheat temperature, and the evaporated mass can be correlated with heat transfer on the basis of energy conservation law. Gopalakrishna et al. [12] set up a time function of flashevaporated mass in a non-dimensional form. The nondimensional function can be used to calculate the evaporated mass and rate during the flash evaporation process of pure water or saline water.

This present study presents a new kinetic model using literature data for water flash evaporation process simulation. In this paper, a new flash evaporation mass model without evaporation-condensation coefficients has been established based on the experimental data of Saury et al. [6], Guo et al. [13], and Yan et al. [14]. This new model has five influencing factors: temperature, superheat, liquid level, evaporator diameter, and time, which is clearly different from those reported. Then, a kinetic model of flash evaporation was obtained using the time derivative of the new evaporation mass model. Finally, a 2D mesh model of the equipment in Ref. [6] was built, and a flash evaporation process of water under various conditions was simulated by Fluent 14.5. The new kinetic model was compared with the wildly used evaporation-condensation model by Lee [15] and Sun et al. [16], as well as the non-dimensional equation by Gopalakrishna et al. [12].

\section{Evaporation Model}

According to many works of literature, the evaporated mass exhibits an exponential relationship with flash evaporation time. Therefore, the mathematical model of volumetric evaporated mass and time can be expressed as follows:

$m_{\mathrm{ev}}=m_{\mathrm{ev}}^{\mathrm{f}}\left(1-\mathrm{e}^{-w t}\right)$

The final volumetric evaporated mass can be influenced by superheat and liquid height $[6,12,17]$. In addition, according to the mass transfer theory, evaporator diameter affects evaporation mass. Thus, the final volumetric evaporated mass can be empirically written as Eq. (2).

$m_{\mathrm{ev}}^{\mathrm{f}}=k_{1} \Delta T^{a_{1}} H^{a_{2}} D^{a_{3}}$

Superheat is determined by the liquid temperature and equilibrium temperature and can be calculated by Eq. (3). The equilibrium temperature of water can be calculated according to an Antoine equation, Eq. (4) [18], under a certain operation pressure.

$\Delta T=T_{0}-T_{\mathrm{e}}$

$\lg p^{*}=7.07406-\frac{1657.46}{T-61.13} \quad(283.15 \mathrm{~K} \leq T \leq 441.15 \mathrm{~K})$

The exponential parameter $(w)$ affects flash evaporation time, which is also called bubble timescale [12] or relaxation time. This physical quantity plays an important role in the flash route of boiling [19] and has been used by Wang et al. [20], Kim and Lior [21], and Khan et al. [22] in flash processes. According to Refs. [4-6, 12, 17] about flash evaporation and the classical mass transfer theory, the parameter ( $w$ ) of Eq. (1) can be simply expressed as a function of superheat, initial temperature, liquid height, and evaporator diameter, and written as Eq. (5).

$w=k_{2} T_{0}^{b_{1}} \Delta T^{b_{2}} H^{b_{3}} D^{b_{4}}$

Therefore, by combining Eqs. (1), (2), and (5), the new model for volumetric evaporated mass can be written as Eq. (6). The model has five independent variables, which are initial temperature, superheat temperature, liquid level, container diameter, and flash time, and nine model parameters: $k_{1}, k_{2}, a_{1}, a_{2}, a_{3}, b_{1}, b_{2}, b_{3}$, and $b_{4}$.

$m_{\mathrm{ev}}=k_{1} \Delta T^{a_{1}} H^{a_{2}} D^{a_{3}}\left[1-\exp \left(-k_{2} T_{0}^{b_{1}} \Delta T^{b_{2}} H^{b_{3}} D^{b_{4}} t\right)\right]$ 


\section{Model Parameter Optimization and Verification}

\section{Model Parameter Optimization}

First, 469 sets of experimental data of volumetric evaporated mass were obtained from Refs. [6, 13, 14]. The original data were obtained from figures in these works using a proportional reading method. Volumetric evaporated mass data at various times were easily obtained from [6], using the evaporation mass data from their figures and the initial solution volume. The other two studies $[13,14]$ directly provide temperature data. Therefore, according to the calculation method of evaporation mass in [6], volumetric evaporated mass can be easily calculated. The data of volumetric evaporated mass from the previous research $[6,13,14]$ are listed in Tables $\mathrm{S} 1$ and $\mathbf{S} 2$. Among them, 305 sets of experimental data (Table S1) were used for model parameter optimization, and the other 164 sets of experimental data (Table S2) were used for model verification. The influencing factor range of flash evaporation experiments in Refs. $[13,14,16]$ is shown in Table 1.

According to their definitions, the values of $k_{1}$ and $k_{2}$ should be greater than 0 . According to the basic law of evaporation [4-6, 12, 17], $a_{1}, a_{3}, b_{1}$, and $b_{4}$ should be larger than 0 , and $a_{2}, b_{2}$, and $b_{3}$ should be less than 0 . Moreover, $a_{2}$ should be in the range of -1 to 0 according to the flash evaporation phenomena [17]. Because of these constraints, the parameters obtained by nonlinear fitting techniques with 305 sets of experimental data are shown as $k_{1}=8.16 \times 10^{8}$, $k_{2}=10^{5}, a_{1}=0.940, a_{2}=-0.436, a_{3}=10.3, b_{1}=2.39$, $b_{2}=-0.753, b_{3}=-0.0639$, and $b_{4}=9.46$.

The regression effect of the new model is shown in Fig. 1, which shows that the numerical results $\left(m_{\mathrm{ev}}^{\prime}\right)$ obtained by Eq. (6) are in good agreement with the literature experimental data $\left(m_{\text {ev }}\right)$; the slope between the literature experimental data and the model values is 0.993 (close to 1), and the correlation index $\left(R^{2}\right)$ is about 0.976 . Moreover, the mean relative error (MRE) between the experimental and model values is about $9.58 \%$.

Statistical analysis was applied to verify the well-posedness of the new model, as shown in Table 2, where $M_{\mathrm{p}}$ is the number of model parameters, $M$ is the number of experimental data, and $S$ is sum of squares of residuals. The values of $\rho^{2}$ and $F$ can be obtained using Eqs. (7) and (8), respectively, and FT

Table 1 Influencing factor range of flash evaporation experiments in Refs. [13, 14, 16]

\begin{tabular}{lllll}
\hline References & $T_{0}\left({ }^{\circ} \mathrm{C}\right)$ & $\Delta T\left({ }^{\circ} \mathrm{C}\right)$ & $H(\mathrm{~m})$ & $D(\mathrm{~m})$ \\
\hline Guo et al. [13] & $65-78$ & $4-14$ & 0.06 & 0.127 \\
Yan et al. [14] & $76.59,64.98$ & 20,13 & 0.05 & 0.127 \\
Saury et al. [6] & $40-74$ & $4-35$ & 0.015 & 0.12 \\
\hline
\end{tabular}

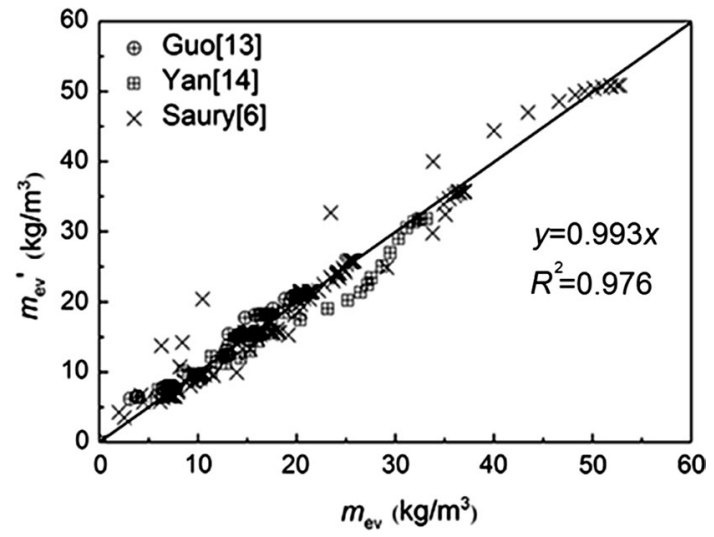

Fig. 1 Numerical data versus experimental data for optimization

is the $F$ value under the corresponding degree of freedom at a significant level of $5 \%$.

$F=\frac{\left[\sum_{i=1}^{M} y_{i}^{2}-\sum_{i=1}^{M}\left(y_{i}-\hat{y}_{1}\right)^{2}\right] / M_{\mathrm{p}}}{\sum_{i=1}^{M}\left(y_{i}-\hat{y}_{1}\right)^{2} /\left(M-M_{\mathrm{p}}\right)}$

$\rho^{2}=1-\sum_{i=1}^{M}\left(y_{i}-\hat{y}_{1}\right)^{2} / \sum_{i=1}^{M} y_{i}^{2}$

When $\rho^{2}$ is bigger than 0.9 and $F$ is bigger than $10 \times \mathrm{FT}$ [23], the model can be considered as well-posed. Therefore, the new model is well-posed according to the statistical data in Table 2.

\section{Model Verification and Comparison}

Additional 164 sets of experimental data were used to verify the practicability of the new model (Table S2). For comparison, a non-dimensional model proposed by Gopalakrishna [12] and the evaporation-condensation model by Lee [15] were used to estimate the volumetric evaporated mass. Gopalakrishna's model [12] can be rewritten as Eq. (9).

$$
\begin{aligned}
m_{\mathrm{ev}}= & 0.8867 \rho_{\mathrm{l}} J_{a} J_{a_{T}}^{0.05} \operatorname{Pr}^{-0.05}\left(\frac{\Delta p}{H}\right)^{-0.05}(1+C)^{a_{4}} \\
& \times\left[1-\exp \left(-\frac{0.27 J_{a_{T}}^{0.133} k}{(\sigma / \Delta p)^{2} \rho_{1} C_{\mathrm{p}}}\left(\frac{\Delta p}{H}\right)^{-1.6} t\right)\right]
\end{aligned}
$$

and

$J_{a}=\frac{C_{\mathrm{p}} \Delta T}{h_{\mathrm{fg}}} \quad J a_{T}=\frac{\rho_{1} C_{\mathrm{p}} \Delta T}{\rho_{\mathrm{v}} h_{\mathrm{fg}}}$

Table 2 Statistics of the new model

\begin{tabular}{llllll}
\hline$M_{\mathrm{p}}$ & $M-M_{\mathrm{p}}$ & $S$ & $\rho^{2}$ & $F$ & $10 \times \mathrm{FT}$ \\
\hline 9 & 296 & 869 & 0.993 & 4541 & 19.1 \\
\hline
\end{tabular}


The coefficient of 0.8867 in Eq. (9) was approximately 0.7 in [6]. Evaporation-condensation model [15] is expressed as:

$v_{\mathrm{ev}}=k_{\mathrm{e}} \rho_{1} \frac{T-T_{\mathrm{e}}}{T_{\mathrm{e}}}$

The parameter $k_{\mathrm{e}}$ is the evaporation coefficient. According to the evaporation-condensation model built in Fluent software, $k_{\mathrm{e}}$ value is taken as 0.1 in this study, and numerical method was applied to calculate the evaporated mass at a time step of $0.0001 \mathrm{~s}$. The error of numerical calculation could be ignored at this time step. Because condensation can be neglected, only evaporation effect was considered during the numerical calculation under the conditions of this study.

Figure 2 shows the relationships between the values calculated by various models and 164 sets of literature experimental data. The slope, $R^{2}, S$, and MRE for different models are shown in Table 3. According to Fig. 2 and Table 3, the new model has the best regression effect, and those of the other two models are obviously poor. The applicability of Gopalakrishna's model may be poor because of the narrow experimental conditions. According to the derivation process of the evaporation-condensation coefficient, the change of liquid temperature will definitely affect the evaporation coefficient. Therefore, the fixed evaporation coefficient will lead to poor calculation effect.

When the volumetric evaporated mass model was obtained, the kinetic model of flash evaporation could be obtained by taking the time derivative of Eq. (6) and can be expressed as follows:
Table 3 Calculation effect of different models

\begin{tabular}{llll}
\hline & New model & $\begin{array}{l}\text { Gopalakrishna's } \\
\text { model [12] }\end{array}$ & $\begin{array}{l}\text { Evaporation-con- } \\
\text { densation model } \\
{[15]}\end{array}$ \\
\hline Slope & 0.986 & 1.138 & 0.789 \\
$R^{2}$ & 0.960 & 0.812 & 0.772 \\
$S$ & 614 & 5198 & 6334 \\
MRE (\%) & 16.3 & 33.9 & 29.2 \\
\hline
\end{tabular}

\section{CFD Simulation}

\section{Model and Methods}

In this investigation, ANSYS Fluent 14.5 was selected to carry out the CFD simulation of water film flash evaporation. The experimental device of Saury et al. [6] was chosen, and the side view of the cylindrical flash chamber is shown in Fig. 3. The flash chamber height is $195 \mathrm{~mm}$, and the inner diameter of the cylindrical section is $120 \mathrm{~mm}$. The diameter for the vapor outlet connected to a vacuum tank is $40 \mathrm{~mm}$.

A 2D model was considered to simplify the workload of the CFD simulation, and an unstructured quadrilateral mesh was used to establish the $2 \mathrm{D}$ mesh model. The grid independence was verified through CFD simulation. Several computational meshes, which differed in mesh densities and number of elements, were chosen for the CFD simulation. By comparing the simulation results of mesh files with different cell numbers, the cell number was determined as 23,400 .

$v_{\mathrm{ev}}=8.16 \times 10^{13} T_{0}^{2.39} \Delta T^{0.187} H^{-0.50} D^{19.8} \exp \left(-10^{5} T_{0}^{2.39} \Delta T^{-0.753} H^{-0.0639} D^{9.46} t\right)$.

The flash evaporation kinetic model was used in the computational fluid dynamics (CFD) simulation of water film flash evaporation.
Six conditions $\left(p=5 \mathrm{kPa}, \Delta T=35{ }^{\circ} \mathrm{C} ; p=10 \mathrm{kPa}\right.$, $\Delta T=24{ }^{\circ} \mathrm{C} ; p=15 \mathrm{kPa}, \Delta T=17,6$, and $1{ }^{\circ} \mathrm{C}$; and $p=20 \mathrm{kPa}$, $\Delta T=10^{\circ} \mathrm{C}$ ) were selected to transiently simulate the water
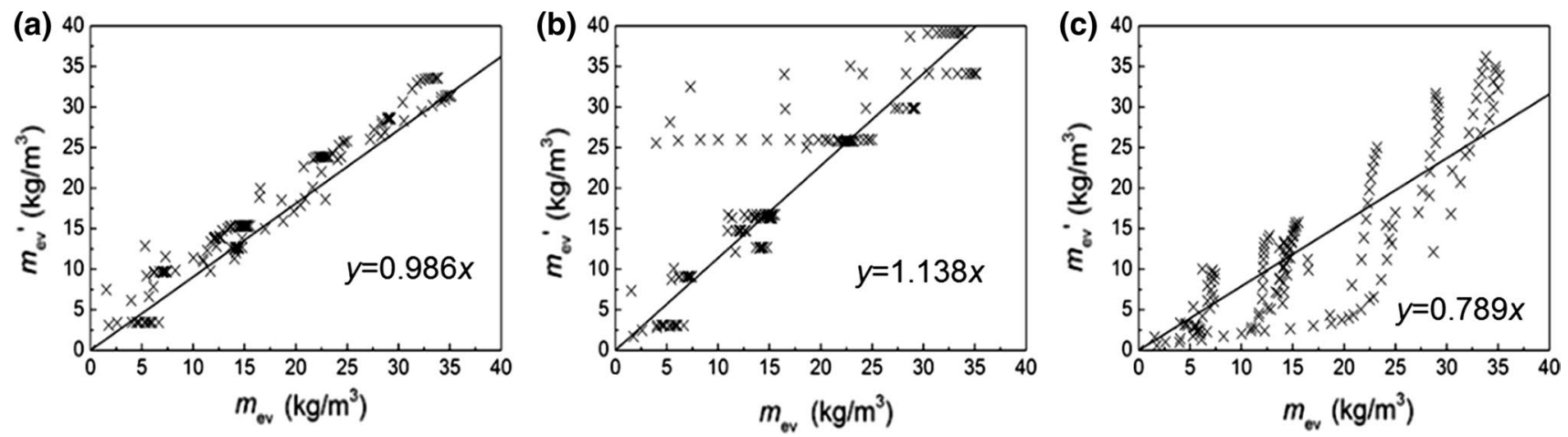

Fig. 2 Comparison between model values and experimental data in the literature. a New model; b non-dimensional model [12]; c evaporationcondensation model [15] 


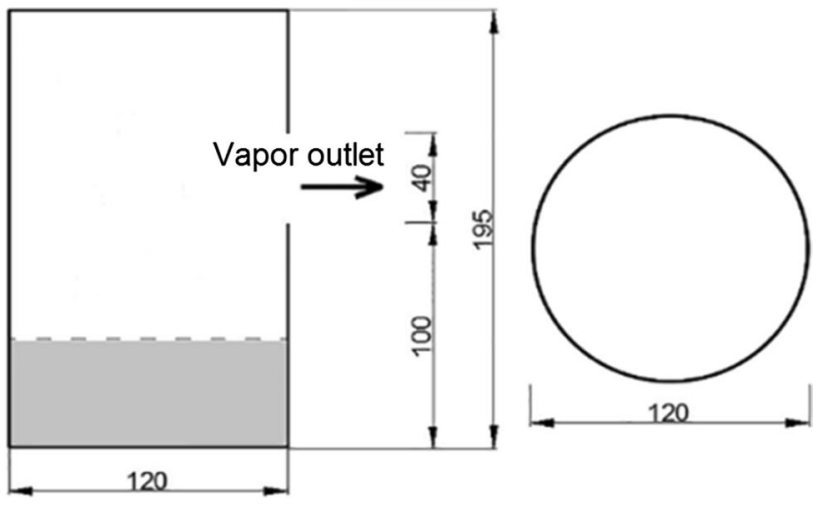

Fig. 3 Side view (left) and top view (right) of the cylindrical flash chamber [6] (Unit: mm)

film flash evaporation for CFD study. To clearly observe the phase distribution during the flashing process, volume-offluid method [24] was used in this work. Water and vapor were, respectively, set as the primary phase and secondary phase. Energy model and standard $k-\varepsilon$ turbulence model were chosen. Vapor outlet was set as the boundary condition of pressure outlet, and walls were considered as adiabatic boundary condition. Gravity and the interactions between the two phases such as surface tension and mass transfer were considered. A user-defined mass transfer function for the kinetic model of Eq. (11) was compiled, interpreted, and introduced into Fluent software. The time step was determined to be $0.0001 \mathrm{~s}$.

\section{Simulated Results}

\section{Distribution Characteristics of Phases and Temperature}

Figure 4 shows the variation of water volume fraction and temperature at $p_{0}=15 \mathrm{kPa}, \Delta T=17^{\circ} \mathrm{C}$. At the beginning of the flash process, the liquid phase fluctuated violently, the phase interface was disrupted entirely, and the phase transition occurred both at the interior and surface. This phenomenon, called boiling, agrees with the concept that flash evaporation belongs to boiling mass transfer and heat transfer processes. As evaporation time grew, the two-phase temperatures decreased quickly, and the flash intensity gradually slowed down since the superheat was reduced. After $5 \mathrm{~s}$, the boiling intensity was greatly reduced and the liquid level gradually decreased. After $15 \mathrm{~s}$, the boiling state almost stopped, and the liquid temperature ranges from 327 to $328 \mathrm{~K}$, which basically corresponds to the equilibrium temperature at an operating pressure of $15 \mathrm{kPa}$. The vapor temperature seems to be higher than the liquid temperature (Fig. 4b) according to the temperature evolution diagram during the flash evaporation process. This phenomenon agrees with the real flash evaporation process [25].

\section{Evaporated Mass and Temperature Evolution}

Figure 5 shows the relationship between CFD simulated evaporation mass and literature values under four different evaporation conditions, and the corresponding results of Gopalakrishna's model and the evaporative-condensation
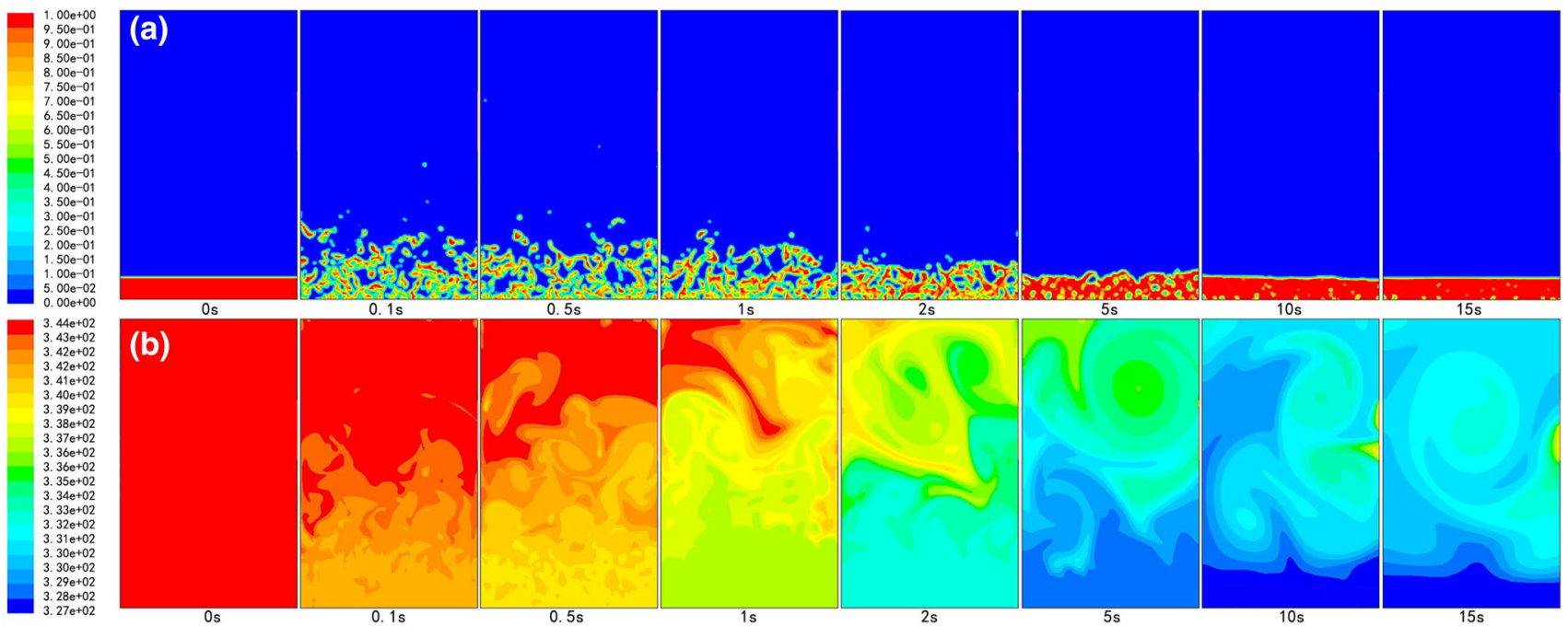

Fig. 4 Flash evaporation phenomena: a phase evolution; $\mathbf{b}$ temperature evolution 
Fig. 5 Comparison of literature evaporation mass and model simulation results: a $p_{0}=5 \mathrm{kPa}$, $\Delta T=35{ }^{\circ} \mathrm{C} ; \mathbf{b} p_{0}=10 \mathrm{kPa}$, $\Delta T=24{ }^{\circ} \mathrm{C} ; \mathbf{c} p_{0}=15 \mathrm{kPa}$, $\Delta T=17^{\circ} \mathrm{C} ; \mathbf{d} p_{0}=20 \mathrm{kPa}$, $\Delta T=10^{\circ} \mathrm{C}$ (a)

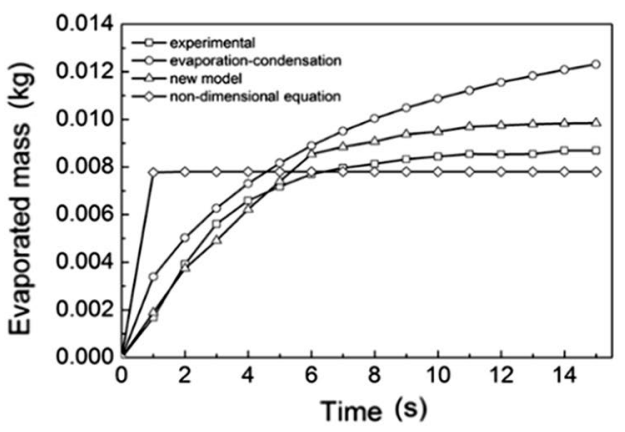

(c)

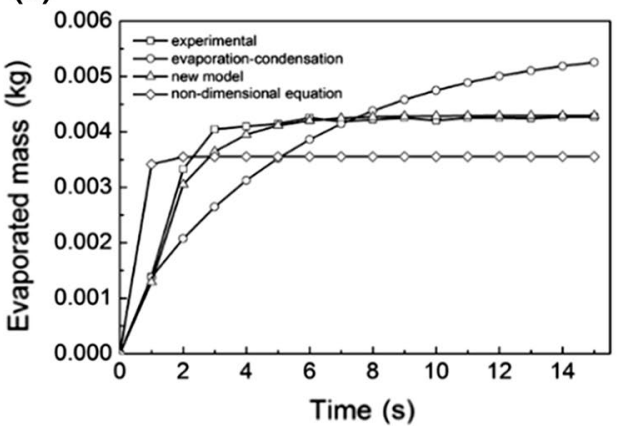

(b)

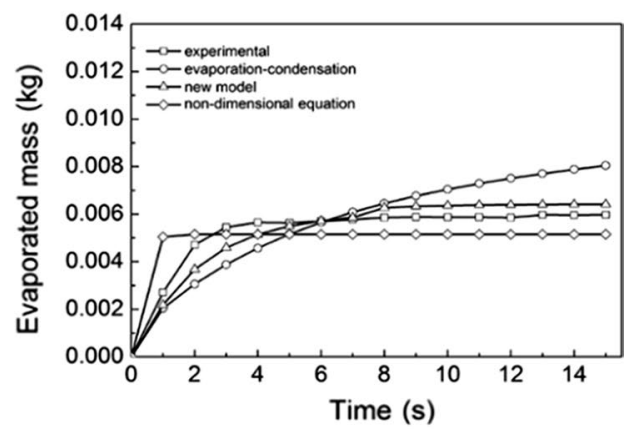

(d)

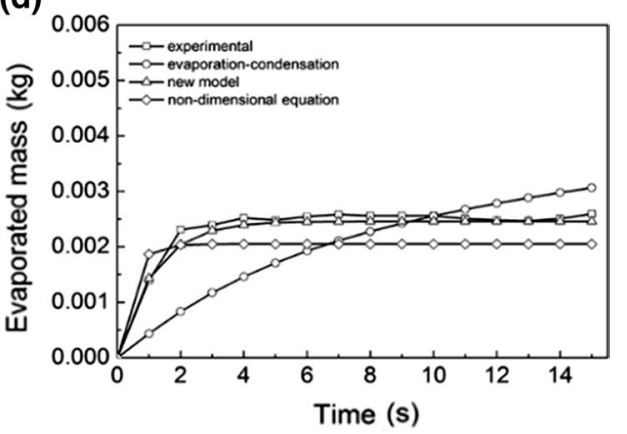

model. The correlation indexes $\left(R^{2}\right)$ and MREs between the experimental and simulation data are shown in Table 4. It is obvious that the simulation data obtained by the new kinetic model are more consistent with the literature experimental results than those of Gopalakrishna's model and the evaporation-condensation model.

Saury et al. [6] used a non-equilibrium function (NEF) to describe temperature variation in the flash evaporation process.
$\mathrm{NEF}=\frac{T(t)-T_{\mathrm{e}}}{T_{0}-T_{\mathrm{e}}}=\left[1+2.8 \times 10^{-3} T_{\mathrm{e}}^{1.3} \Delta T\right]^{-t /\left(44 \Delta T^{0.55} T_{\mathrm{e}}^{-0.86)}\right.}$

Figure 6 shows the relationship between the CFD simulation temperature and literature values under four evaporation conditions, and the corresponding results of Eq. (12) and the evaporative-condensation model. The consistency between model data and experimental values is shown in Table 4. The
Table $4 R^{2}$ and MRE of mass and temperature for various models

\begin{tabular}{|c|c|c|c|c|c|}
\hline \multirow[t]{2}{*}{ Conditions } & \multirow[t]{2}{*}{ Model } & \multicolumn{2}{|c|}{ Evaporated mass } & \multicolumn{2}{|c|}{ Temperature } \\
\hline & & $R^{2}$ & $\operatorname{MRE}(\%)$ & $\overline{R^{2}}$ & $\operatorname{MRE}(\%)$ \\
\hline \multirow{4}{*}{$\begin{array}{l}p_{0}=5 \mathrm{kPa} \\
\Delta T=35^{\circ} \mathrm{C}\end{array}$} & Evaporation-condensation & 0.951 & 31.0 & 0.972 & 12.2 \\
\hline & Equation (11) & 0.984 & 11.0 & 0.986 & 7.73 \\
\hline & Equation (12) [6] & - & - & 0.959 & 11.2 \\
\hline & Gopalakrishna’s model [12] & 0.678 & 39.7 & - & - \\
\hline \multirow{4}{*}{$\begin{array}{l}p_{0}=10 \mathrm{kPa} \\
\Delta T=24^{\circ} \mathrm{C}\end{array}$} & Evaporation-condensation & 0.807 & 21.0 & 0.816 & 13.7 \\
\hline & Equation (11) & 0.936 & 8.85 & 0.930 & 3.83 \\
\hline & Equation (12) [6] & - & - & 0.871 & 6.68 \\
\hline & Gopalakrishna's model [12] & 0.872 & 16.1 & - & - \\
\hline \multirow{4}{*}{$\begin{array}{c}p_{0}=15 \mathrm{kPa} \\
\Delta T=17^{\circ} \mathrm{C}\end{array}$} & Evaporation-condensation & 0.764 & 16.3 & 0.752 & 8.14 \\
\hline & Equation (11) & 0.987 & 2.67 & 0.986 & 0.75 \\
\hline & Equation (12) [6] & - & - & 0.878 & 2.78 \\
\hline & Gopalakrishna's model [12] & 0.829 & 23.6 & - & - \\
\hline \multirow{4}{*}{$\begin{array}{c}p_{0}=20 \mathrm{kPa} \\
\Delta T=10^{\circ} \mathrm{C}\end{array}$} & Evaporation-condensation & 0.674 & 25.9 & 0.695 & 3.89 \\
\hline & Equation (11) & 0.972 & 3.73 & 0.969 & 0.62 \\
\hline & Equation (12) [6] & - & - & 0.846 & 1.56 \\
\hline & Gopalakrishna's model [12] & 0.938 & 19.2 & - & - \\
\hline
\end{tabular}


Fig. 6 Relationships between temperature and time: $\mathbf{a}$ $p_{0}=5 \mathrm{kPa}, \Delta T=35^{\circ} \mathrm{C} ; \mathbf{b}$ $p_{0}=10 \mathrm{kPa}, \Delta T=24^{\circ} \mathrm{C} ; \mathbf{c}$ $p_{0}=15 \mathrm{kPa}, \Delta T=17^{\circ} \mathrm{C} ; \mathbf{d}$ $p_{0}=20 \mathrm{kPa}, \Delta T=10^{\circ} \mathrm{C}$
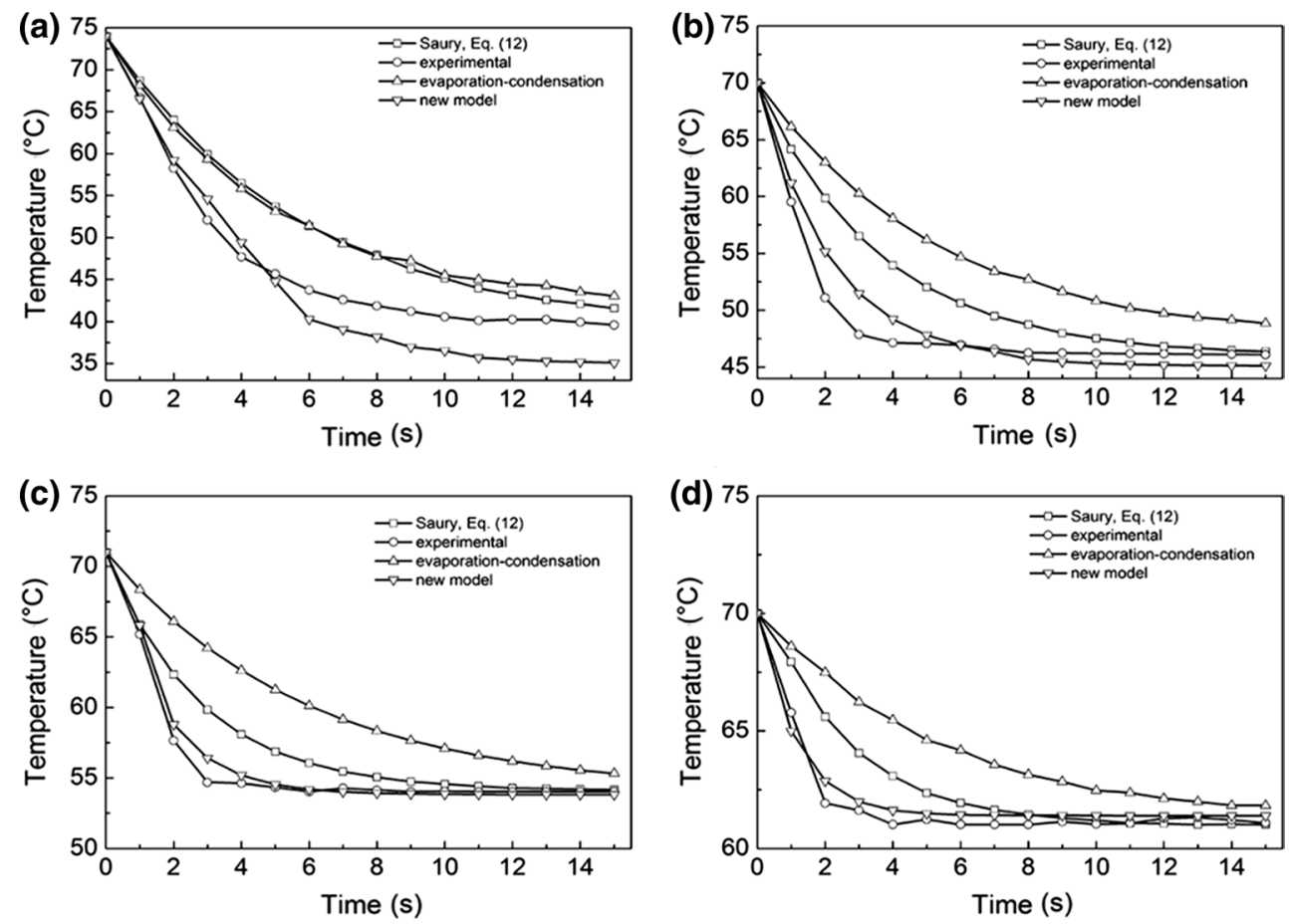

\section{Conclusions}

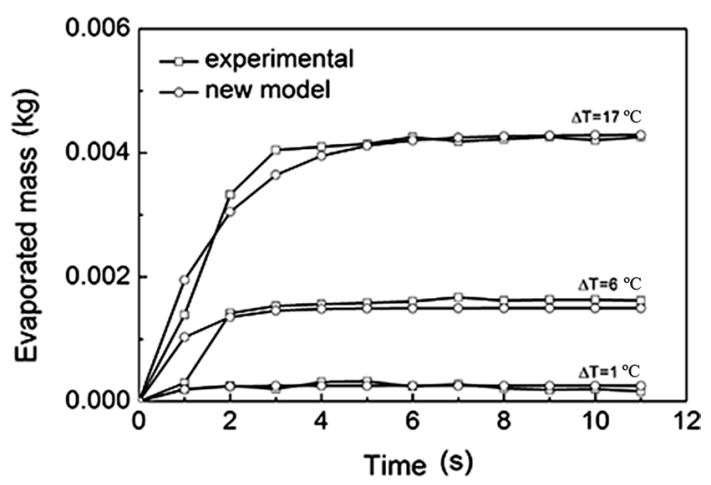

Fig. 7 Comparison of literature mass and the results simulated by the new kinetic model at $15 \mathrm{kPa}$

temperature variation corresponds to the evaporated mass variation. It is clear that the temperature curve of the new kinetic model coincides more with the experimental data in the literature, compared with Eq. (12) and the evaporative-condensation model.

Figure 7 shows the simulated values and experimental data versus time when the operating pressure is $15 \mathrm{kPa}$, and the superheat is 17,6 , and $1{ }^{\circ} \mathrm{C}$. The results show that the simulation data for several superheats coincide with the experimental data.
Through this study on the flash evaporation of water, some main conclusions can be drawn:

1. A new flash evaporation mass model, which has nine model parameters and five influencing factors (i.e., temperature, superheat, liquid height, evaporator diameter, and time), was established. Model optimization and verification with a large number of literature data indicate that the new model is effective, and the model was proved to be well-posed by a statistical analysis.

2. A new kinetic model of the flash evaporation of water was obtained on the basis of the new mass model.

3. With the combination of this new kinetic model and Fluent software through a user-defined function program, the water flash evaporation process under different conditions was simulated by volume-of-fluid multiphase model. The simulated results of phase distribution, temperature variation, and evaporated mass by CFD method show that the new kinetic model has a good application effect.

Acknowledgements This study was supported by the Scientific Research Special Fund of Marine Public Welfare Industry (No. 20140508), National Natural Science Foundation of China (No. 51478308), and Natural Science Foundation of Tianjin (No. 14JCYBJC23300). 
Open Access This article is distributed under the terms of the Creative Commons Attribution 4.0 International License (http://creativeco mmons.org/licenses/by/4.0/), which permits unrestricted use, distribution, and reproduction in any medium, provided you give appropriate credit to the original author(s) and the source, provide a link to the Creative Commons license, and indicate if changes were made.

\section{References}

1. Liu J, Aizawa Y, Yoshino H (2005) Experimental and numerical study on indoor temperature and humidity with free water surface. Energy Build 37(4):383-388

2. Zhang Y, Wang J, Liu J et al (2013) Experimental study on heat transfer characteristics of circulatory flash evaporation. Int J Heat Mass Transf 67:836-842

3. Zhang Y, Wang J, Yan J et al (2014) Experimental study on nonequilibrium fraction of $\mathrm{NaCl}$ solution circulatory flash evaporation. Desalination 335(1):9-16

4. Miyatake O, Tomimura T, Ide Y et al (1981) An experimental study of spray flash evaporation. Desalination 36(2):113-128

5. Miyatake O, Tomimura T, Ide Y et al (1981) Effect of liquid temperature on spray flash evaporation. Desalination 37(3):351-366

6. Saury D, Harmand S, Siroux M (2002) Experimental study of flash evaporation of a water film. Int J Heat Mass Transf 45(16):3447-3457

7. Knudsen $M$ (1915) The maximum evaporation rate of mercury. Ann Phys 352(13):697-708 (in German)

8. Badam VK, Kumar V, Durst F et al (2008) Experimental and theoretical investigations on interfacial temperature jumps during evaporation. Exp Therm Fluid Sci 32(1):276-292

9. Cheng WL, Chen H, Hu L et al (2015) Effect of droplet flash evaporation on vacuum flash evaporation cooling: modeling. Int J Heat Mass Transf 84:149-157

10. Cheng WL, Zhang WW, Chen $\mathrm{H}$ et al (2016) Spray cooling and flash evaporation cooling: the current development and application. Renew Sustain Energy Rev 55:614-628

11. Aoki I (2015) Analysis of characteristics of water flash evaporation under low-pressure conditions. Heat Transf Asian Res 29(1):22-33
12. Gopalakrishna S, Purushothaman VM, Lior N (1987) An experimental study of flash evaporation from liquid pools. Desalination 65:139-151

13. Guo Y, Deng W, Yan J et al (2008) Influence of the initial condition on pool water instantaneous flash evaporation. J Eng Thermophys 29(8):1335-1338 (in Chinese)

14. Yan J, Dan Z, Wei D et al (2008) Experimental investigation of the instantaneous mass transfer coefficient at steam-liquid interface during water film flash evaporation in closed chamber. J Xi' an Jiaotong Univ 42(5):515-518 (in Chinese)

15. Lee WH (2013) Computational methods for two-phase flow and particle transport. World Scientific, Singapore

16. Sun D, Xu J, Chen Q (2014) Modeling of the evaporation and condensation phase-change problems with fluent. Numer Heat Transf Part B 66:326-342

17. Saury D, Harmand S, Siroux M (2005) Flash evaporation from a water pool: influence of the liquid height and of the depressurization rate. Int J Therm Sci 44(10):953-965

18. Shi J, Wang JD, Yu GC et al (1996) Manual of chemical engineering, 2nd edn. Chemical Industry Press, Beijing (in Chinese)

19. Liu Y, Olewski T, Véchot LN (2015) Modeling of a cryogenic liquid pool boiling by CFD simulation. J Loss Prev Process Ind 35:125-134

20. Wang Y, Yu L, Zhang Y et al (2016) Experimental study on circulatory flash speed of aqueous $\mathrm{NaCl}$ solution circulatory flash evaporation. Desalination 392:74-84

21. Kim JI, Lior N (1997) Some critical transitions in pool flash evaporation. Int J Heat Mass Transf 40(10):2363-2372

22. Khan MM, Hélie J, Gorokhovski M et al (2017) Experimental and numerical study of flash boiling in gasoline direct injection sprays. Appl Therm Eng 123:377-389

23. Dontchev AL, Zolezzi T (2006) Well-posedness in the calculus of variations. In: Dold A, Eckmann B, Takens F (eds) Well-posed optimization problems. Springer, Heidelberg

24. Hirt CW, Nichols BD (1981) Volume of fluid (VOF) method for the dynamics of free boundaries. J Comput Phys 39(1):201-225

25. Popov S, Melling A, Durst F et al (2005) Apparatus for investigation of evaporation at free liquid-vapour interfaces. Int $\mathrm{J}$ Heat Mass Transf 48(11):2299-2309 